\title{
Identifikasi Gas Hidrat pada Cekungan Simeuleu di Lintasan BGR- 135 Menggunakan Analisis AVO (Amplitude Versus Offset)
}

\author{
Rahmi Nanda Pertiwi ${ }^{1 *}$, Trevi Jayanti Puspasari², Elistia Liza Namigo ${ }^{1}$, Dwi \\ Pujiastuti $^{1}$ \\ ${ }^{1}$ Laboratorium Fisika Bumi, Jurusan Fisika, FMIPA, Universitas Andalas \\ Kampus Unand, Limau Manis, Padang, 25163 \\ ${ }^{2}$ Balai Teknologi Survei Kelautan, Badan Pengkajian dan Penerapan Teknologi (BPPT), Jalan \\ M. H Thamrin No.8, Jakarta 10340 \\ *tiwirahmi23@gmail.com
}

\begin{abstract}
ABSTRAK
Pengolahan data seismik laut 2D menghasilkan indikasi adanya gas hidrat pada lintasan BGR-135 yang kemudian divalidasi dengan analisis Amplitude Versus Offset (AVO). Daerah penelitian berlokasi di Cekungan Simeuleu yang terdapat di pantai barat Sumatera. Software ProMax digunakan untuk pengolahan data seismik dan Software HRS (Humpson Russel) untuk analisis AVO. Pengolahan data seismik dimulai dari input raw data serta dilakukan proses prosesing (filtering, editing, dekonvolusi, analisis kecepatan, stacking, migrasi) hingga didapatkan output berupa data pre stack dan post stack. Data post stack kemudian diinterpretasi untuk menentukan zona fokus yang mengindikasikan keberadaan gas hidrat yang ditandai dengan kenampakan Buttom Simulating Reflector (BSR). Dari hasil interpretasi, indikasi kehadiran BSR terdapat pada CDP 26318 sampai 26354 dan TWT 1590 ms sampai 1660 ms. Data seismik pre stack yang telah ditentukan batasan CDP dan kedalaman dari zona fokus, dijadikan input untuk analisis AVO. Analisis AVO dilakukan pada rentang daerah target di lapisan terindikasi BSR dengan menentukan nilai gradient dan crossplot. Dari analisis diperoleh nilai gradient positif dan crossplot berada pada kuadran AVO kelas III. Gradient positif menandakan adanya anomali amplitudo pada zona fokus sedangkan AVO kelas III menandakan adanya indikasi hidrokarbon pada zona fokus.

Kata kunci : Analisis Versus Offset (AVO), Gas hidrat, Bottom Simulating Reflector (BSR), Cekungan Simeuleu
\end{abstract}

\begin{abstract}
The prosesing of seismic marine 2D indicated BSR in line BGR-135 which then validated by AVO Analysis. Research area is located in forearc basin Simeuleu - West Coast of Sumatera. Promax used for processing marine seismic 2D data and HRS (Humpson Russel) used for AVO analysis. Seismic data processing was carried out with raw data as input which then going through filtering, editing, deconvolution, velocity analysis, stacking and migration resulted in pre stack and post stack data as ouputs. Post-stack data is interpreted to determine zone of interest which indicates the presence of gas hydrate with the appearance of a Buttom Simulating Reflector (BSR). Then, the seismic pre stack data (which the CDP limit and the depth of the focus zone has been determined) is used as input for AVO analysis. Indication of BSR is identified at CDP 26318 to 26354 and depth $1590 \mathrm{~ms}$ to $1660 \mathrm{~ms}$. AVO Analysis is applied in the target through gradient and crossplot analysis. AVO analysis shows that the gradient is positive and the crossplot resulted in AVO class III. Positive gradient indicates that there is amplitude anomaly in the target zone while AVO class III indicates hydrocarbon content in the zone.

Keywords: Analysis Versus Offset (AVO), Gas hydrate, Bottom Simulating Reflector (BSR), Simeuleu Basin
\end{abstract}

\section{PENDAHULUAN}

Sumber energi saat ini umumnya berasal dari sumber energi fosil seperti batubara, minyak, dan gas bumi yang membutuhkan waktu jutaan tahun dalam pembentukannya. Saat ini permintaaan manusia terhadap bahan bakar fosil khususnya minyak bumi semakin tinggi, sehingga cadangannya diperkirakan menipis untuk belasan tahun ke depan (Skkmigas, 2018). Oleh karena itu, para peneliti terus mengupayakan mencari sumber energi baru sebagai alternatif bahan bakar fosil, salah satunya adalah gas hidrat (Kvenvolden, 1998).

Gas hidrat (methane hydrate) merupakan suatu material padat yang terbentuk dari susunan molekul air dan gas yang terperangkap di dalam struktur kristal hidrat (cathrate) (Dagar dan Joshi, 2013). Gas hidrat berpotensi terbentuk pada daerah yang memiliki temperatur rendah dan tekanan tinggi seperti pada daerah kutub dan daerah laut (Wang dan Dongyang, 2017). Umumnya gas hidrat menempati ruang pori yang ada pada sedimen baik berupa 
pelapisan, semen, nodul, vein atau dyke (Triarso dan Troa, 2017). Gas hidrat termasuk hidrokarbon nonkonvensional karena gas hidrat berbentuk, berasal dan diperoleh dengan cara yang tidak biasa dibandingkan dengan hidrokarbon konvesional (minyak dan gas bumi) (Singh dan Prakash, 2015). Metan hidrat berbentuk padat dan terbentuk oleh molekul $\mathrm{CH}_{4}$ yang dikelilingi oleh 20 molekul air sebagai pengikatnya (Dagar dan Joshi, 2013). Gas metana mengandung sedikit karbon dibandingkan gas lain sehingga memiliki tingkat emisi karbon $\left(\mathrm{CO}_{2}\right)$ yang rendah. Oleh karena itu, gas hidrat merupakan salah satu energi alternatif yang ramah lingkugan untuk menekan terjadinya pemanasan global.

Tujuan dari penelitian ini yaitu melakukan identifikasi keberadaan gas hidrat pada penampang seismik 2D. Identifikasi gas hidrat ditandai dengan adanya Bottom Simulating Reflektor (BSR) pada profil seismik. BSR merupakan indikasi awal keberadaan gas hidrat pada sedimen laut. Karakteristik BSR diataranya memiliki bentuk menyerupai seafloor, polaritas terbalik dan memotong statigrafi batuan (Bachrudin dkk., 2016). BSR terlihat pada profil seismik karena adanya kontras impedansi antara lapisan gas hidrat dengan lapisan lainnya. Penelitian dan eksplorasi mengenai gas hidrat telah banyak dilakukan di berbagai negara terutama negara maju dan minim sumber energi fosil seperti U.S, Kanada, Jepang, Rusia sedangkan di Indonesia masih dalam tahap riset. Triarso dan Troa (2017) melakukan identifikasi gas hidrat di Cekungan Simeuleu pada lintasan BGR -136 dengan hasil ditemukannya BSR sebagai indikasi utama gas hidrat. Kemudian, Sing dan Prakash (2015) melakukan penelitian yang sama di Cekungan Andaman India dengan menerapkan metode AVO dan Inversi dengan hasil ditemukannya BSR sebagai indikasi utama gas hidrat dan Hato dkk. (2014) melakukan penelitian di Cekungan Nangkai Jepang menerapkan metode AVO dengan hasil ditemukannya BSR tetapi tidak terdapat gas hidrat (fluida) pada indikasi BSR tersebut. Oleh karena itu, untuk mengetahui kandungan fluida yang terdapat di lapisan BSR maka digunakan suatu metode sebagai bentuk validasi keberadaan gas hidrat yaitu analisis Amplitudo Versus Offset (AVO). Prinsip dari analisis ini yaitu mengetahui adanya anomali pada profil seismik ditandai dengan membesarnya amplitudo seiring bertambahnya offset (jarak dari source ke receiver) serta diketahui nilai anomali kelas AVO pada zona target yang terindikasi BSR (Hato dkk., 2014).

\section{METODE}

\subsection{Data}

Data yang digunakan dalam penelitian ini yaitu lintasan BGR-135, hasil survei laut dalam pada ekspedisi "Sea Cause II"oleh Indonesia (BPPT) dan Jerman (BGR) pada tahun 2006. Fokus lokasi berada di perairan barat Sumatera (Aceh) yang secara tatanan geologi menempati Cekungan Busurmuka Simeulue. Lintasan BGR-135 merupakan salah satu daerah yang terindikasi adanya gas hidrat di Cekungan Simelue dengan panjang $215 \mathrm{~km}$. Jenis data seismik yang digunakan adalah data seismik 2D dengan format data SEG-Y.

\subsection{Pengolahan Data}

Penelitian ini menggunakan dua jenis software yaitu software ProMAX 2D Version 5000.0.2.0 untuk pengolahan data mentah (raw data) hingga didapatkan profil seismik dan software Humpson Russel (HRS) version 8.R3.1 untuk interpretasi dalam memvalidasi keberadaan gas. Proses pengolahan data pada penelitian ini terdiri dari dua tahap yaitu pengolahan yang dimulai dari raw data hingga dihasilkan output berupa data pre stack (gather seismik ) dan post stack (profil seismik). Tahapan kedua yaitu pengolahan data pre stack untuk analisis AVO pada zona target.

\subsection{Pengolahan Data Seismik Pre Stack dan Post Stack}

\subsubsection{Input Data}

Tahap ini merupakan langkah awal dalam proses pengolahan data seismik laut 2D. Pada tahap ini, data yang didapatkan akan diinput ke dalam software ProMAX yang bertujuan untuk mempermudah pembacaan data pada tahapan selanjutnya. Data yang akan diinput merupakan data raw yang telah mengalami reformating dalam index SEG-Y. 


\subsubsection{Geometry Assisgnment}

Tahap ini merupakan tahapan penggabungan dan pencocokan data yang telah diinput sebelumnya (raw data) dengan data parameter akuisisi di lapangan pada observer log. Penggabungan data ini dilakukan untuk mempermudah dalam penyajian data pada proses pengolahan data seismic. Data seismik mentah (raw data) hanya mengandung informasi berupa nilai station, FFID, dan channel. Hasil geometri akan menampilkan informasi tambahan berupa koordinat shot point, koordinat receiver, koordinat CDP, offset, dan lainnya.

\subsubsection{Filtering}

Tahap ini merupakan tahap untuk memisahkan frekuensi sinyal data seismik dengan frekuensi noise sehingga dapat menentukan design frekuensi yang akan digunakan. Parameter filtering ditentukan dengan spectral analysis untuk mendapatkan frekuensi yang dianggap sebagai data.

\subsubsection{Preprosesing}

Tahapan preprosesing bertujuan untuk menghilangkan atau menyeleksi data dengan kualitas buruk yang terjadi pada saat akusisi sehingga mengganggu dalam proses pengolahan data selanjutnya. Tahapan preprosesing terdiri dari tahapan editing, TAR, dekonvolusi.

\subsubsection{Velocity Analysis}

Tahap ini merupakan tahap analisis kecepatan sebagai bentuk kecepatan yang tepat pada kedalaman lapisan tertentu yang akan ditunjukkan oleh semblance kecepatan dengan energi yang tinggi.

\subsubsection{Stacking}

Tahap ini merupakan tahap untuk menampilkan penampang seismik sebagai penjumlahan trace-trace seismik yang diurutkan berdasarkan CDP dengan mengaplikasikan proses Normal Move Out (NMO).

\subsubsection{Migrasi}

Tahap migrasi merupakan tahap untuk mengembalikan reflektor miring ke posisi 'aslinya' serta untuk menghilangkan efek difraksi akibat sesar, kubah garam, pembajian, dengan tujuan untuk menghasilkan penampang seismik yang tidak jauh berbeda dengan struktur asli.

\subsection{Analisis AVO}

\subsubsection{Data}

Input dari data ini yaitu data gather hasil pre-stack. Data gather disimpan pada folder data yang telah dibuat sebelumnya di salah satu directory pada komputer yaitu direktori D.

\subsubsection{Proses pengolahan}

Pengolahan data difokuskan kepada jendela AVO, dengan data import berupa data gather dalam format SEG-Y yang telah disimpan di folder data. Data di import pada sub menu super gather atau angle gather dengan mengatur jumlah CDP, depth, angle yang disesuaikan pada zona target yang telah ditentukan melalui profil seismik hasil data post stack.

\subsubsection{Picking Analisis}

Proses picking analisis dilakukan setelah picking horizon ada zona target dengan memberikan nama horizon yang sesuai. Horizon yang telah ditentukan selanjtunya dilakukan picking analisis.

\subsubsection{Gradient analisis dan crosplot}

Gradient analisis dan crosplot dilakukan pada daerah yang telah dilakukan picking horizon. Hasil gradient analisis menampilkan kurva gradient dan crossplot yang memperlihatkan trend /kelas klasifikasi anomali AVO pada zona target. 


\section{HASIL DAN DISKUSI}

\subsection{Pengolahan Data Seismik Pre Stack dan Post Stack}

Pengolahan data pre-stack dimulai dari pengolahan raw data dengan input data berupa format SEG-Y . Ouput dari raw data akan menampilkan penampang seismik yang memiliki banyak noise (Gambar 1) dan dibutuhkan tahapan filtering untuk membuang noise-noise dalam meningkatkan nilai $\mathrm{S} / \mathrm{N}$ ratio. Raw data memiliki informasi yang minim dan belum disesuaikan dengan hasil akusisi, maka diperlukan proses geometery untuk mencocokan data seismik dengan hasil akusisi di lapangan. Proses geometry juga bertujuan untuk memberikan infomasi lebih mengenai parameter seismik yang digunakan pada tahap selanjutnya. Dalam proses filtering jenis filter yang digunakan yaitu bandpass filter karena data seismik terdiri data high dan low frekuensi. Frekuensi yang dianggap sebagai data pada penelitian ini yaitu 6-12-60-120 $\mathrm{Hz}$.

Data hasil filtering telah menunjukkan bentuk dari penampang seismik tetapi masih memiliki noise pada bagian atasnya (Gambar 2) sehinnga diperlukan tahapan preprosesing (Editing, TAR, Deconvolusi). Jenis editing yang digunakan yaitu editing top mute karena noise yang akan dibuang terletak pada bagian atas dari data. Hasil top mute selanjutnya dilakukan proses True Amplitudo Recovery (TAR) yang bertujuan untuk mengkover ulang data seismik yang mengalami atenuasi amplitudo. Atenuasi terjadi pada daerah yang dalam, karena semakin dalam suatu daerah mengakibatkan penjalaran gelombang seismik mengalami atenuasi. Proses TAR dilakukan dengan memasukkan hasil parameter tes yang tepat dengan nilai $6 \mathrm{db} / \mathrm{sec}$. Tahap selanjutnya yaitu melakukan proses dekonvolusi yang bertujuan untuk mengembalikan frekuensi yang hilang oleh bumi serta mengembalikan bentuk wavelet menjadi semakin spike. Tahap dekonvolusi dilakukan setelah menentukan nilai parameter dekonvolusi yang diperoleh melalui tahapan autokorelasi yaitu menentukan nilai dari operator length dan lag. Dalam penelitian ini operator length dan lag yang digunakan yaitu $14 \mathrm{~ms}$ dan $262 \mathrm{~ms}$. Hasil dari dekonvolusi menampilkan data seismik yang lebih bersih dari noise dan bentuk wavelet yang lebih spike (Gambar 3). Pada tahap dekonvolusi dapat dilakukan proses pemotongan data dengan mempersempit daerah pengolahan yang difokuskan pada range zona target. Data dipotong pada CDP 24000-26990.

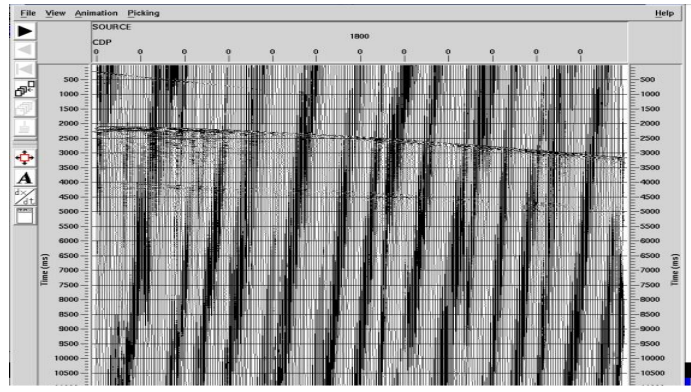

Gambar 1 Hasil raw data

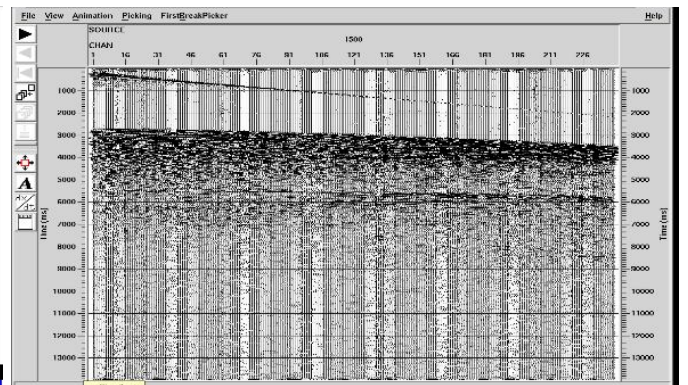

Gambar 2 Hasil Filtering

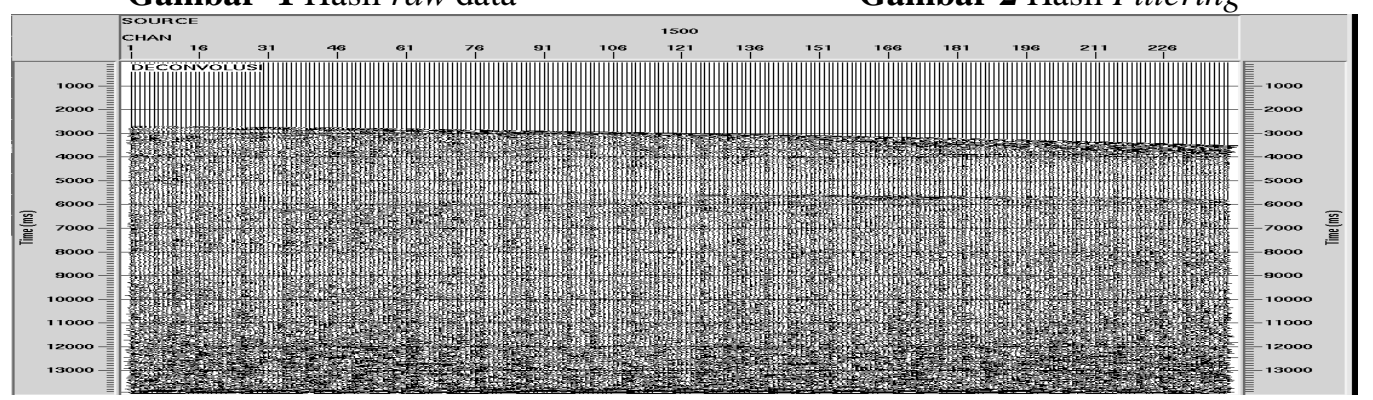

Gambar 3. Hasil dekonvolusi setelah melewati tahapan reprosesing

Tahapan preprosesing merupakan tahapan untuk menghilangkan noise dasar pada data seismik, selanjutnya dilakukan proses velocity analysis, stacking dan migrasi. Proses velocity analisis merupakan tahapan terpenting dalam peneltian ini, picking kecepatan yang dilakukan diharapkan sesuai dengan kecepatan pada zona target hingga didapatkan nilai kecepatan yang 
tepat. Metode picking velocity yang dilakukan yaitu picking semblance yang diwakili dalam kontur warna (Gambar 4).

a)

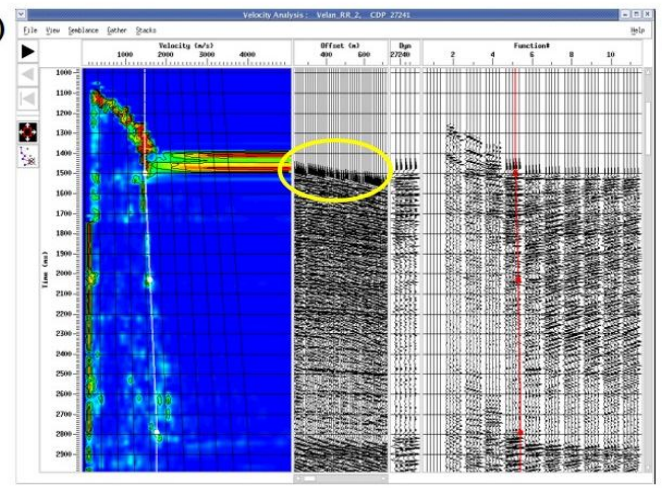

b)

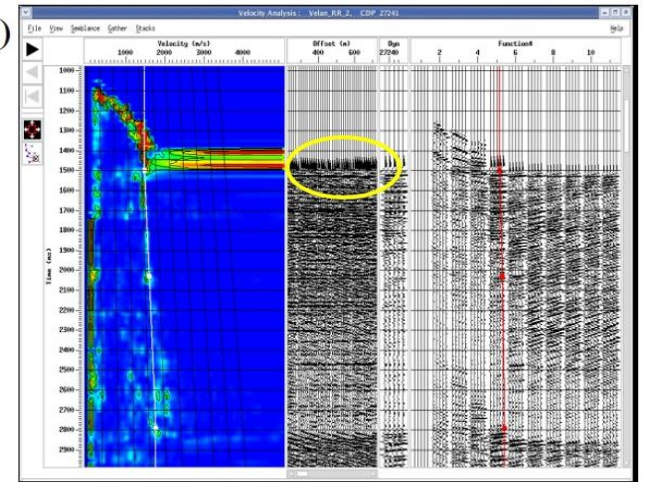

Gambar 4 Jendela proses velocity analysis. a) Picking sembalance velocity sebelum NMO dan (b) Picking semblance velocity setelah NMO

Kontur warna menunjukkan tingkatan kecepatan, proses picking velocity diharapkan memiliki nilai kecepatan yang bertambah seiring dengan bertambahnya kedalaman. Gambar 4a merupakan hasil picking velocity tanpa dilakukan koreksi NMO sedangkan Gambar 4b hasil picking velocity setelah koreksi NMO. Koreksi NMO bertujuan untuk meluruskan kembali reflektor yang miring seperti pada Gambar 4b. Ouput dari koreksi NMO menghasilkan nilai kecepatan untuk digunakan pada analisis AVO. Proses selanjutnya yaitu stacking yang bertujuan untuk menjumlahkan trace-trace seismik yang diurut berdasarkan nilai CDP. Hasil stacking sudah dapat menampilkan profil seismik tetapi profil tersebut masih memiliki beberapa noise seperti data multiple dan bowtie. Noise hasil stacking dihilangkan dengan proses migrasi yang bertujuan untuk mengembalikan posisi reflektor hingga menyerupai bentuk litologi bumi yang sebenarnya. Hasil dari migrasi dapat memperlihatkan profil seismik sehingga dapat dilakukan interpetasi seismik untuk mendeteksi keberadaan BSR (Gambar 5). Gambar 5a merupakan hasil interpretasi seismik dalam mendeteksi karakteristik BSR seperti memotong struktur dan menyerupai seafloor sedangkan Gambar 5b merupakan perbesaran dari zona target (lingkaran kuning) untuk melihat pembalikan polaritas (tanda panah).

a)

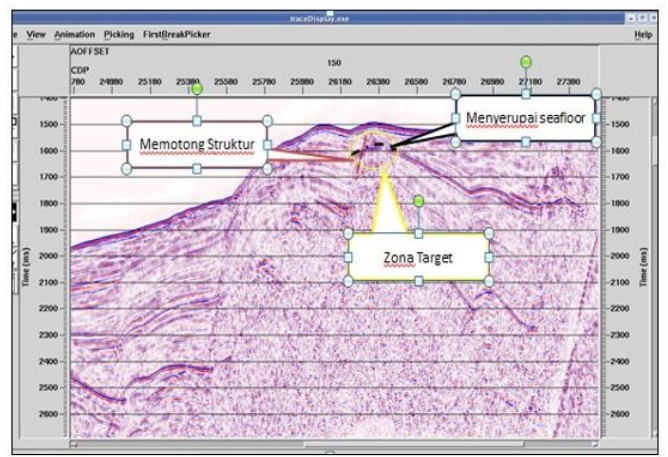

b)

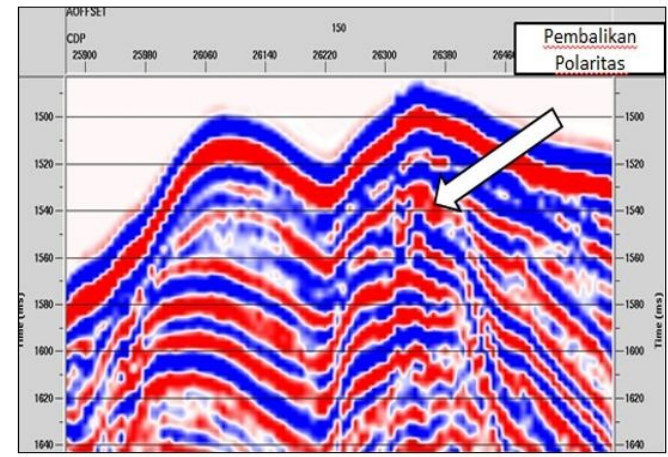

Gambar 5 Deteksi BSR pada profil seismic berdasarkan karakteristik BSR a) Indikasi BSR (memotong struktur dan menyerupai seafloor) b) Polaritas terbalik pada zona target.

\subsection{Analisis AVO}

Pengolahan analisis AVO menggunakan data input CDP gather berupa data prestack gather. Data prestack gather yaitu data seismik dalam CDP gather yang setiap CDP terdiri beberapa trace berdasarkan sudut angle yang diterima receiver. Data CDP gather yang digunakan dari CDP 26318 sampai CDP 26354 dan mulai dari TWT 1600 ms sampai TWT 1620 ms sedangkan data kecepatan yang digunakan adalah $R M S$ velocity. 


\subsubsection{Picking Analysis}

Picking analysis bertujuan untuk menentukan nilai gradient hasil picking horizon pada zona target yang terindikasi BSR. Data dikategorikan terindikasi BSR apabila hasil picking horizon pada zona target menampilkan nilai gradient positif. Gambar 6a hingga 6d menunjukkan nilai gradient positif pada zona target yang diwakilkan oleh garis warna biru.

a)

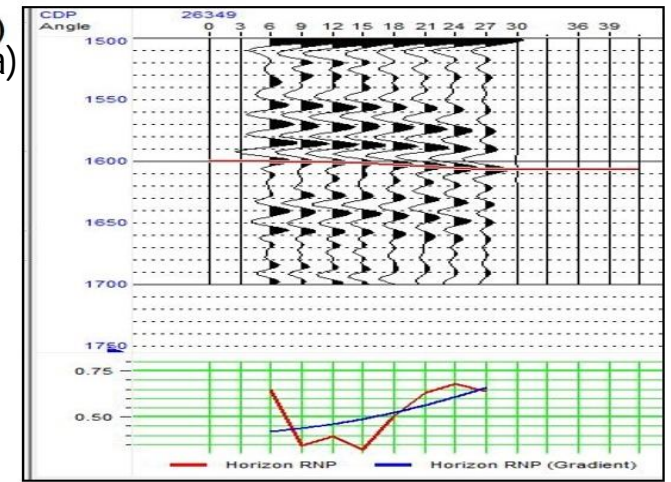

c)

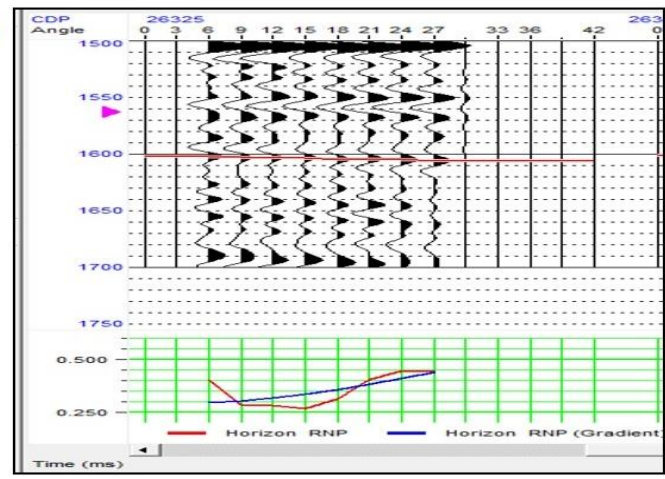

b)

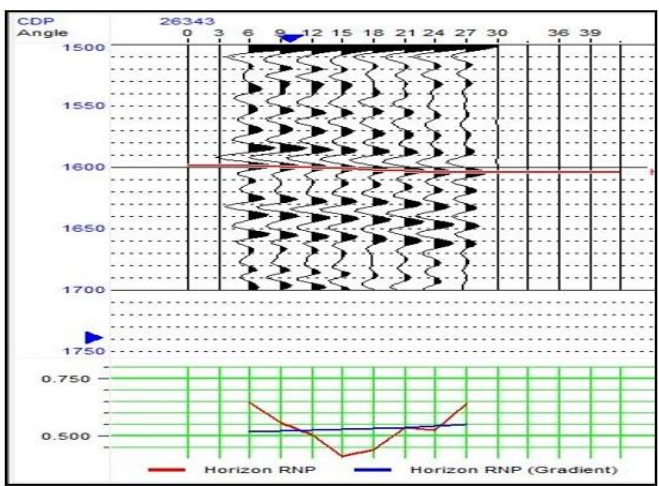

d)

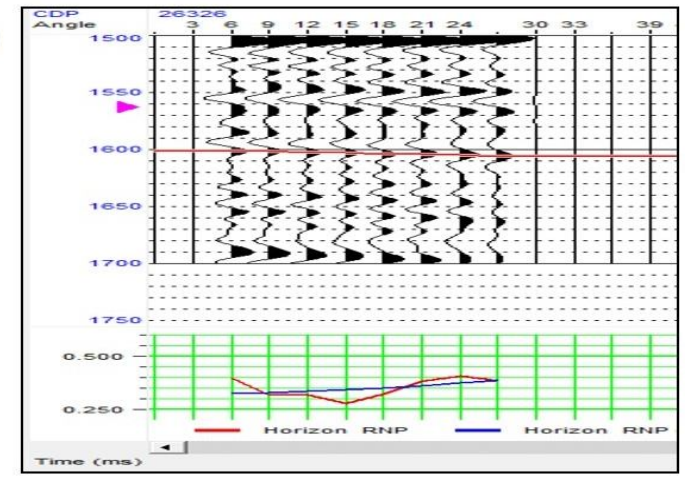

Gambar 6. Picking analisis pada CDP a) 26325 b) 26326 c) 26349 d) 26343

\subsubsection{Gradient Analisis dan Crossplot}

Proses picking analisis tidak secara langsung menentukan trend/class gas pada zona target maka dilanjutkan dengan analisis gradient dan crossplot. Produk hasil perkalian antara nilai A dan B menghasilkan nilai positif serta nilai amplitudo yang bertambah besar seiring kenaikan sudut. Kemudian, hasil crossplot pada zona target menunjukkan AVO kelas III (Gambar 7) yang mengindikasikan adanya BSR sebagai indikasi utama gas hidrat.

a)

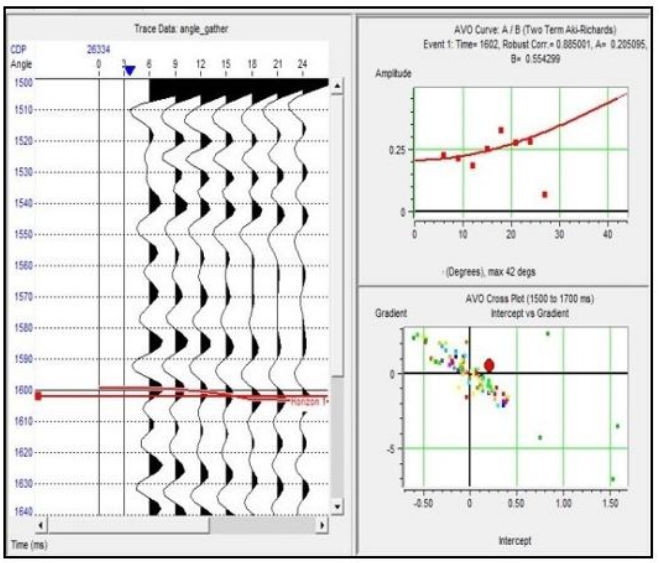

b)

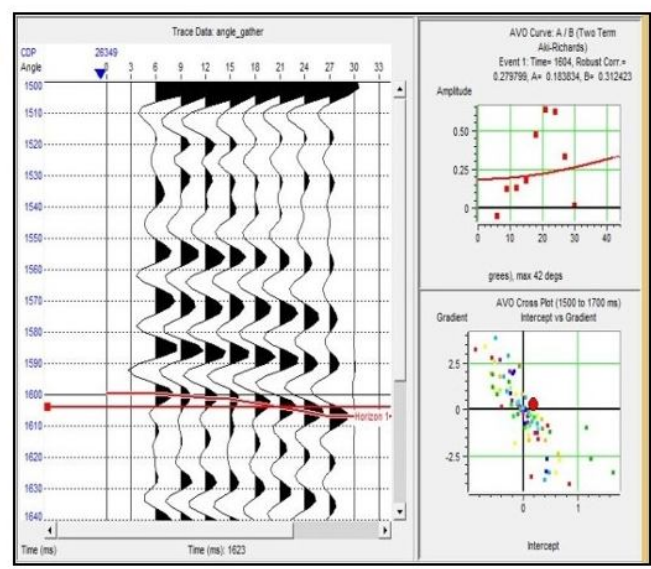


c)

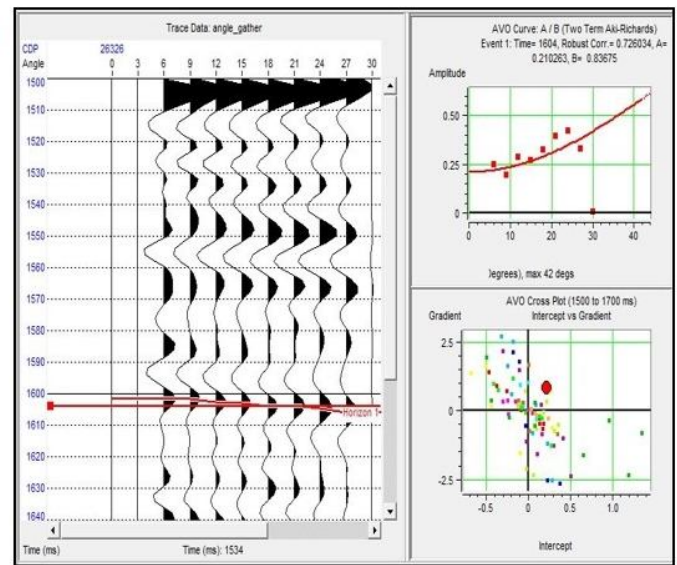

d)

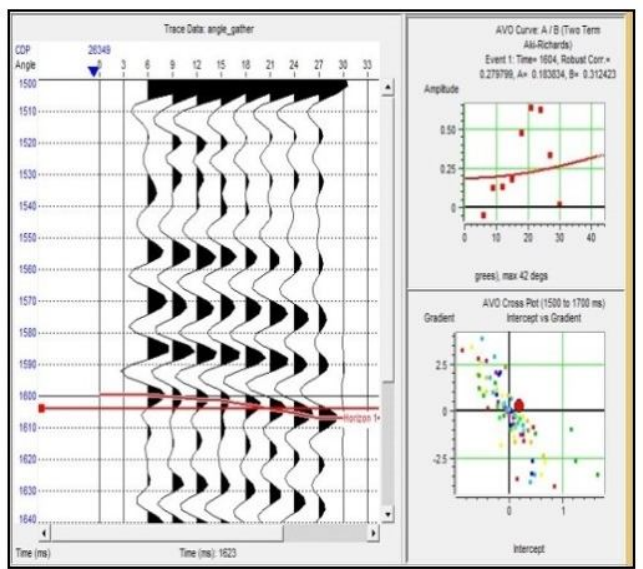

Gambar 7. Gradient analsis dan crossplot pada CDP a) 26325 b) 26326 c) 26349 d) 26343

Gambar 7a dan 7b memiliki grafik gradient analysis yang sesuai dengan hasil picking horizon sedangkan Gambar 7c dan 7d memiliki bentuk grafik yang sedikit menyimpang dari hasil picking horizon. Hal itu terjadi karena adanya ketidaktepatan nilai kecepatan ketika dilakukan picking velocity.

\section{KESIMPULAN}

Berdasarkan pengolahan data seismik laut 2D pada lintasan BGR-135 di Cekungan Simeuleu ditemukan indikasi keberadaan gas hidrat yaitu BSR. BSR terindikasi pada CDP 26318 sampai CDP 26354 pada kedalaman 1600 ms sampai 1620 ms. Hasil analisis AVO pada daerah terindikasi BSR menunjukkan anomali amplitudo yang ditandai dengan nilai gradient positif dan karakter AVO kelas III yang kemungkinan terisi gas.

\section{DAFTAR PUSTAKA}

Bachrudin A., Firmansyah Y., dan Sunardi E., Studi Awal Identifikasi Gas Hidrat Menggunakan Metode Seismik di Lapangan YF, Selat Makassar, Seminar Nasional keII FTG Universitas Padjajaran, Bandung (2016).

Dagar, S dan Joshi, A. Gas Hydrates - A New Horizon, 10th Biennial International Conference \& Exposition, Dhanbad (Jharkhand), India, (2013).

Hato, M., Inamori, T., Bahar, A., dan Matsuoka, T., Application of AVO Analysis to Seismik Data for Detection of Gas below Methane Hydrate Stability Zone in Nankai Trough Area, Resource geology, Vol. 54, ITB, hal. 105-113, `(2004).

Kvenvolden, K.A., A Primer on the Geoogica Occurrence of Gas Hydrate. Organic Geochemistry, USGS.USA, 137, hal. 9-30, (1993).

Singh, NP dan Prakash A., Natural Gas Hydrat in India Prospect Identification, Production Tecnologist and Associated Challenges, Journal of Geography, Enviroment and Eart Science Internasional, 3, hal. 1-2, (2015).

Triarso, E. dan Troa RA., Indikasi Keberadaan Gas Hidrat pada Cekungan Busur Muka Simeulue Dan Potensinya Sebagai Sumber Energi Masa Depan, Jurnal Kelautan Nasional, Badan Penelitian dan Kelautan RI , 11, hal. 130, (2017).

Wang, X. dan Dongyan, P., Application of AVO attribute Inversion technology to gas hydrate identification in the Shenhu Area, South China Sea, Marine and Petroleum Geology, Elseivier, 80, hal. 23-31, (2017).

Skkmigas, 2017, Cadangan Energi Indonesia, www.skkmigas.go.id, diakses pada 16 Maret 2018 